\title{
Prognostic value of bilirubin and drug interactions
}

\author{
Alexander $\mathrm{Ng}$
}

Dear Editor:

I read with interest the results presented by Weber and colleagues, ${ }^{1}$ regarding the correlations between at-admission liver function parameters, and severity of COVID-19 infection. The authors reported that over half $(57.6 \%)$ of the cohort presented with any liver function abnormality on admission. Adjusted for age, gender, and comorbidities, hypoalbuminaemia was the most predictive of severe COVID-19 (OR 9.95, $\mathrm{p}<0.001)$. This was followed by AST elevation (OR 2.54, $\mathrm{p}=0.005$ ), and ALT elevation (OR 2.10, $\mathrm{p}=0.030$ ). Total bilirubin elevation was the most predictive singular factor of COVID-19-related death (OR 4.80, $\mathrm{p}=0.032$ ). The predictive value was doubled when combined with hypoalbuminaemia (OR 9.64, $\mathrm{p}=0.024$ ).

However, there are concerns as to whether the predictive value of bilirubin in COVID-19 is fully explored in the study. Total bilirubin comprises direct (conjugated) bilirubin, and indirect (unconjugated) bilirubin. The normal values for total bilirubin and direct bilirubin are, respectively, at $1.2 \mathrm{mg} / \mathrm{dL}$, and $0.3 \mathrm{mg} / \mathrm{dL} .{ }^{2}$ Direct bilirubin indicates the presence of cholestasis. Yet, from the study, only $4.6 \%$ of the cohort experienced total bilirubin elevation at admission. The figure rose to $19.8 \%$ at peak level. This formed a contrast with the much higher prevalence gammaglutamyltransferase (GGT) elevation (At admission: 36.9\%; peak level: $59.9 \%$ ), which is another marker for biliary disease. Furthermore, the least

Faculty of Laws, University College London, London, UK

Correspondence to Dr Alexander Ng, Faculty of Laws, University College London, London WC $1 \mathrm{H}$ OEG, UK; a.ng.20@ucl.ac.uk patients experienced total bilirubin elevation both at admission, and at peak, relative to other recorded liver parameters.

COVID-19 infection entails a hyperinflammatory response. The increase in inflammatory activity may impact on indirect bilirubin levels. According to pre-clinical models, inflammation decreases UGT1A1, UGT1A9, and UGT2B5 mRNA expression. ${ }^{3}$ This might be related to specific cytokine changes. Glucuronidation was inhibited $51 \%$ by IL- 6 expression at 24 hours in porcine hepatocytes. ${ }^{4}$ As COVID-19 is associated with increased IL-6 levels, ${ }^{5}$ glucuronidation in COVID-19 patients is expected to be further dampened. Hence, by logic, indirect bilirubin levels increase with disease severity. There is also evidence of cholangiocyte injury due to higher ACE2 expression - a key target of SARS-CoV-2. ${ }^{6}$ In addition to that a substantial proportion of patients experienced GGT elevation, direct bilirubin should also increase. It is therefore interesting why only a small proportion of the cohort experienced total bilirubin elevation. An even more surprising note is that only total bilirubin elevation and hypoalbuminaemia were significantly correlated with COVID-19-related mortality. Total bilirubin elevation was not significantly associated with severe COVID-19.

Such interesting correlations can be explored further by elucidating the changes of direct and indirect bilirubin levels in patients with
COVID-19. There is a possibility that the increase of either is compensated by the decrease of the other, via different mechanisms. Another point of interest is the role of drugs. The authors have commented that since at-admission (baseline) parameters were used for prognostication, drug-induced liver injury is unlikely. Adjustment was also made for comorbidities. However, since many patients have chronic diseases (arterial hypertension: $53.0 \%$; diabetes mellitus type II: $23.5 \%$; coronary artery disease: $19.8 \%$ ), it is likely that chronic medication is taken. Such medications can introduce variations to the study findings by interacting with COVID19-related medication, and/or causing liver injury. Moreover, drug regimens can lead to fluctuations in bilirubin levels. The importance of investigating direct and indirect bilirubin levels separately is augmented by recent studies showing that direct bilirubin, and indirect bilirubin/ direct bilirubin ratio are predictive of disease severity. ${ }^{78}$

There is thus an attraction to clarify the prognostic value of bilirubin levels in COVID-19 infection, preferably by analysing direct and indirect bilirubin levels separately.

Twitter Alexander Ng @tigersss2007

Contributors The sole author is responsible for all aspects of the production of the manuscript.

Competing interests None declared.

Patient consent for publication Not required.

Provenance and peer review Not commissioned; internally peer reviewed.

Open access This is an open access article distributed in accordance with the Creative Commons Attribution Non Commercial (CC BY-NC 4.0) license, which permits others to distribute, remix, adapt, build upon this work non-commercially, and license their derivative works on different terms, provided the original work is properly cited, appropriate credit is given, any changes made indicated, and the use is non-commercial. See: http://creativecommons.org/ licenses/by-nc/4.0/.

(C) Author(s) (or their employer(s)) 2021. Re-use permitted under CC BY-NC. No commercial re-use. See rights and permissions. Published by BMJ.

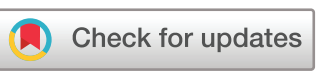

To cite Ng A. BMJ Open Gastro 2021;8:e000625. doi:10.1136/bmjgast-2021-000625 
BMJ Open Gastro 2021;8:e000625.

doi:10.1136/bmjgast-2021-000625

ORCID iD

Alexander Ng http://orcid.org/0000-0001-7463-7563

\section{REFERENCES}

1 Weber S, Hellmuth JC, Scherer C, et al. Liver function test abnormalities at hospital admission are associated with severe course of SARS-CoV-2 infection: a prospective cohort study. Gut 2021: gutjnl-2020-323800.

2 Bilirubin test - Mayo Clinic, 2021.

Available: https://www.mayoclinic org/tests-procedures/bilirubin/about/ pac-20393041\#: :text=Typically\%2C\% 20 you'll\%20get\%20results,slightly\%20 from $\% 20$ laboratory\%20to\%20laboratory [Accessed 6 Feb 2021].

3 Richardson TA, Sherman M, Kalman $\mathrm{D}$, et al. Expression of UDP. glucuronosyltransferase isoform mRNAs during inflammation and infection in mouse liver and kidney. Drug Metab Dispos 2006;34:351-3.

4 Monshouwer M, Witkamp RF, Nujmeijer $\mathrm{SM}$, et al. Suppression of cytochrome P450- and UDP glucuronosyl transferasedependent enzyme activities by proinflammatory cytokines and possible role of nitric oxide in primary cultures of pig hepatocytes. Toxicol Appl Pharmacol 1996;137:237-44.
5 Zhang J, Hao Y, Ou W, et al. Serum interleukin- 6 is an indicator for severity in 901 patients with SARS-CoV-2 infection: a cohort study. J Trans/ Med 2020;18:406.

6 Kumar P, Sharma M, Kulkarni A, et al. Pathogenesis of liver injury in coronavirus disease 2019. J Clin Exp Hepatol 2020;10:641-2.

7 Liang W, Liang H, Ou L, et al. Development and validation of a clinical risk score to predict the occurrence of critical illness in hospitalized patients with COVID-19. JAMA Intern Med 2020;180:1081.

8 Liu Z, Li J, Long W. Bilirubin levels as potential indicators of disease severity in coronavirus disease patients: a retrospective cohort study. Front Med 2020:7. 